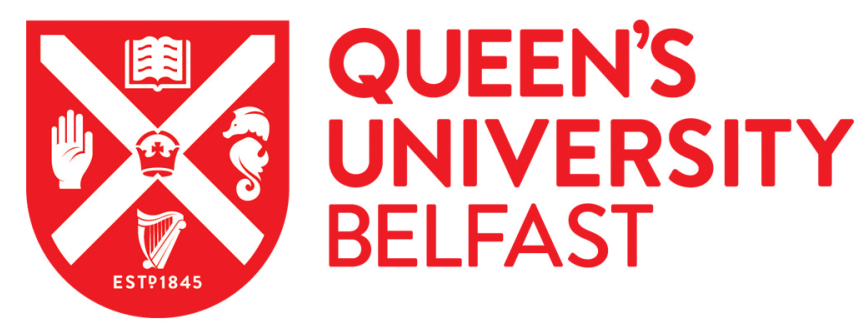

\title{
Quality of life in men living with advanced and localised prostate cancer in the UK a population-based study
}

Downing, A., Wright, P., Hounsome, L., Selby, P., Wilding, S., Watson, E., Wagland, R., Kind, P., Donnelly, D. W., Butcher, H., Catto, J. W. F., Cross, W., Mason, M., Sharp, L., Weller, D., Velikova, G., McCaughan, E., Mottram, R., Allen, M., ... Glaser, A. W. (2019). Quality of life in men living with advanced and localised prostate cancer in the UK a population-based study. Lancet Oncology, 20(3), 436-447. https://doi.org/10.1016/S14702045(18)30780-0

Published in:

Lancet Oncology

Document Version:

Peer reviewed version

Queen's University Belfast - Research Portal:

Link to publication record in Queen's University Belfast Research Portal

\section{Publisher rights}

(C) 2019 Elsevier Ltd. All rights reserved.

This manuscript version is made available under the CC-BY-NC-ND 4.0 license http://creativecommons.org/licenses/by-nc-nd/4.0/,which permits distribution and reproduction for non-commercial purposes, provided the author and source are cited.

\section{General rights}

Copyright for the publications made accessible via the Queen's University Belfast Research Portal is retained by the author(s) and / or other copyright owners and it is a condition of accessing these publications that users recognise and abide by the legal requirements associated with these rights.

Take down policy

The Research Portal is Queen's institutional repository that provides access to Queen's research output. Every effort has been made to ensure that content in the Research Portal does not infringe any person's rights, or applicable UK laws. If you discover content in the Research Portal that you believe breaches copyright or violates any law, please contact openaccess@qub.ac.uk. 


\section{Quality of life in men living with advanced and localised prostate cancer: A United Kingdom population-wide patient-reported outcome study of 30,000 men}

\section{Authors:}

Amy Downing, Penny Wright, Luke Hounsome, Peter Selby, Sarah Wilding, Eila Watson, Richard Wagland, Paul Kind, David W Donnelly, Hugh Butcher, James WF Catto, William Cross, Malcolm Mason, Linda Sharp, David Weller, Galina Velikova, Eilis McCaughan, Rebecca Mottram, Majorie Allen, Therese Kearney, Oonagh McSorley, Dyfed W Huws, David H Brewster, Emma McNair, Anna Gavin*, Adam W Glaser* *Joint senior authors.

Leeds Institute of Medical Research at St James's, University of Leeds, Leeds, UK (A Downing PhD, P Wright PhD, Prof P Selby DSc, S Wilding PhD, H Butcher MSc, Prof G Velikova PhD, R Mottram BHSc, M Allen MSc, Prof A W Glaser DM);

Leeds Institute of Data Analytics, University of Leeds, Leeds, UK (A Downing PhD, S Wilding PhD, R Mottram BHSc, M Allen MSc, Prof A W Glaser DM);

National Cancer Registration and Analysis Service, Public Health England, Bristol, UK (L Hounsome PhD);

Leeds Teaching Hospitals NHS Trust, Leeds, UK (Prof P Selby DSc, W Cross PhD, Prof A W Glaser DM);

Department of Midwifery, Community and Public Health, School of Nursing and Midwifery, Oxford Brookes University, Oxford, UK (Prof E Watson PhD);

Faculty of Health Sciences, University of Southampton, Southampton, UK (R Wagland PhD); Academic Unit of Health Economics, University of Leeds, Leeds, UK (Prof P Kind MPhil); Northern Ireland Cancer Registry, Queen's University Belfast, Belfast, UK (D W Donnelly PhD, T Kearney PhD, A Gavin MB BCh BAO);

School of Nursing and Midwifery, Queen's University Belfast, UK (O McSorley PhD); Academic Urology Unit, University of Sheffield, Sheffield, UK (J W F Catto PhD);

Division of Cancer and Genetics, School of Medicine, Cardiff University, Cardiff, UK (Prof M Mason MD);

Institute for Health \& Society, Newcastle University, Newcastle upon Tyne, UK (Prof L Sharp $\mathrm{PhD})$; 
Usher Institute of Population Health Sciences and Informatics, University of Edinburgh, Edinburgh, UK (Prof D Weller PhD);

Institute of Nursing and Health Research, Ulster University, Coleraine, UK (Prof E McCaughan $\mathrm{PhD}$ );

Welsh Cancer Intelligence and Surveillance Unit, Public Health Wales, Cardiff, UK (D W Huws $\mathrm{MSc}$ );

Information Services Division, NHS National Services Scotland, Edinburgh, UK (E McNair $\mathrm{PhD})$.

\section{Corresponding author:}

Dr Amy Downing,

Leeds Institute for Data Analytics,

Level 11 Worsley Building,

University of Leeds,

Leeds, LS2 9NL

Tel: +44 1133430308

Email: a.downing@leeds.ac.uk 


\section{Research in context}

\section{Evidence before this study}

Ovid databases (MEDLINE, Embase, PsychINFO) were searched for articles relating to health-related quality of life (HRQL) and "localised", "advanced", "metastatic", "stage" and "prostate cancer" or "prostatic neoplasms" from June 1996 to June 2018. Studies were excluded if they had no measure of health-related quality of life and were included if they included men with either early, late or combined stage prostate cancer. Most articles relate to men with localised disease, with good quality evidence collected in the setting of clinical trials and observational studies of specific cohorts. Few studies have focused on those diagnosed with locally advanced or metastatic prostate cancer (PCa). In the small number of studies separating results by stage, poorer HRQL has been associated with later stage of disease. However, sample sizes tend to be small. Therefore, little is known about the impacts of PCa in men living with and beyond a diagnosis of advanced disease, especially in comparison to men with non-metastatic disease.

\section{Added value of the study}

To our knowledge, this is first study able to compare, at scale, the HRQL and functional outcomes of men living with localised and advanced PCa. Data were collected on 35,823 men, with diagnostic stage available on 30,733 of whom $23.4 \%$ had stage III disease and $12.8 \%$ stage IV. The population-based approach enables true definition of the quality of survival of the increasingly prevalent group of men living with and beyond PCa. We identified that men with stage III and IV disease reported more problems, including those generic to health and those related to treatment, particularly androgen deprivation therapy (ADT). Poor sexual function was reported by most men, regardless of stage, and the majority $(55.8 \%)$ reported not being offered any intervention or support for this. Despite specific functional morbidities, many men with PCa self-reported their overall health to be similar to men in general population studies and a substantial proportion of men with stage IV disease $(23.5 \%)$ 
reported no problems on any EQ-5D dimension. These results highlight areas of unmet need and will be vital in helping men make informed decisions about their treatment.

\section{Implications of all the available evidence}

Most men living 18-42 months after a diagnosis of PCa can expect to experience as good HRQL as men in the general population, including those with stage III and a substantial proportion of those with stage IV disease. Although sexual morbidity is common, the majority of men are not offered helpful intervention or support. The evidence suggests that there are subgroups of men who would benefit from service improvements around sexual rehabilitation and measures to minimise the use of ADT. These include wider use of intermittent ADT (versus continuous use), the avoidance of unnecessary ADT (i.e. for non-metastatic disease) and the use of shorter neoadjuvant courses (reduced from 3 years to 1 year). This study collected data from men living up to a maximum of 42 months beyond diagnosis. Those with stage IV disease are likely to experience deterioration in their HRQL at some point following this. Further evidence is needed to inform appropriate service provision for them in these later years. 


\section{Abstract}

Background: Little is known about the health-related quality of life (HRQL) of men living with advanced prostate cancer. We report population-wide functional outcomes and HRQL in men with all stages of prostate cancer, and identify implications for healthcare delivery.

Methods: Men alive 18-42 months after diagnosis of prostate cancer were identified through cancer registration data. A postal survey was administered which contained validated measures to assess a) functional outcomes (EPIC-26 plus use of interventions for sexual dysfunction) and b) generic HRQL (EQ-5D-5L \& self-assessed health). Log-linear and binary logistic regression models were used to compare functional outcomes and HRQL across diagnostic stage and self-reported treatment groups.

Findings: $35,823(60.8 \%)$ men responded. Stage was known for $85.8 \% ; 19,599(63.8 \%)$ stage I/II, 7,209 (23.4\%) stage III, 3,925 (12.8\%) stage IV. Functional outcomes: Poor sexual function was common (81.0\%), regardless of stage, and over half of men (55.8\%) received no intervention for this. Differences in urinary and bowel morbidity were greater with respect to treatment than stage. In men treated with androgen deprivation therapy (ADT), 30.7\% reported moderate/big problems with hot flushes, $29.4 \%$ with lack of energy and $22.5 \%$ with weight gain. HRQL: Overall self-assessed health was similar in men with stage I-III disease, and whilst reduced in those with stage IV cancer, $23.5 \%$ with metastatic disease reported no problems on any EQ-5D dimension.

Interpretation: Men diagnosed with advanced disease do not report markedly different HRQL outcomes to those diagnosed with localised disease, although substantial problems with hormonal function and fatigue are reported amongst men treated with ADT. Sexual dysfunction is common and the majority of men are not offered helpful intervention or support. Service improvements around sexual rehabilitation and measures to reduce the impact of ADT are required.

Funding: The Movember Foundation, in partnership with Prostate Cancer UK. 


\section{Background}

The number of prostate cancer (PCa) survivors has increased rapidly over recent decades. According to population-based cancer registry data, 10-year survival has tripled in the last 40 years in the United Kingdom (UK) ${ }^{1}$. In England, there are an estimated 325,000 men alive having been diagnosed with PCa between 1995 and 2015². A principal challenge for healthcare is to understand the needs of this growing group of men, in particular the problems and challenges faced by those living with advanced disease $(30 \%$ of men with distant metastases now survive at least five years $\left.{ }^{3}\right)$. The quality of survival experienced, with definition of the specific impacts of the disease and its treatment, must be robustly determined to facilitate appropriate care provision ${ }^{4}$.

Significant sexual, urinary and bowel morbidities have been identified following treatment of localised PCa, with the pattern and severity of morbidity varying according to the type and intensity of treatment received ${ }^{5-8}$. Most intelligence originates from randomised controlled trials and observational studies of specific cohorts, often reporting outcomes following surgery compared to radiotherapy and surveillance in men with localised $\mathrm{PCa}^{9}$. Evidence for the UK has not been generated at an unselected population level. In addition, few studies have reported outcomes in men with locally advanced or metastatic disease. Such studies tend to be small and are mostly clinical trials comparing specific treatment types ${ }^{10-12}$.

The Life After Prostate Cancer Diagnosis (LAPCD) study adopts an established approach to the measurement of population-level health-related quality of life (HRQL), previously used in a national population of colorectal cancer survivors ${ }^{13}$, and extends this to men living with all stages of PCa 18-42 months post diagnosis. This timeframe was chosen as it represents the period when initial treatment is complete and side effects/HRQL have begun to stabilise ${ }^{5}$. In men with advanced disease, treatment with androgen deprivation therapy (ADT) starts at diagnosis and therefore any ADT-related effects would be captured. An internationally recommended series of outcome measures has been utilised to facilitate comparison and 
interpretation, with specific enquiry as to the impact of interventions offered for sexual dysfunction ${ }^{14}$.

Here we quantify and compare a) functional outcomes (urinary, bowel, sexual and vitality/hormonal) and b) HRQL of men with $\mathrm{PCa}$ across all disease stages and treatment groups, and identify implications for healthcare delivery.

\section{Methods}

The LAPCD methodology has been reported in full ${ }^{15}$ but is outlined below.

\section{Study design and participants}

All National Health Service (NHS) Hospital Trusts/Health Boards treating PCa in the UK were approached. In England, 111 of 136 Trusts participated; 21 declined and 4 were involved in overlapping studies. All Trusts/Health Boards in Northern Ireland ( $\mathrm{Nl} ; n=5)$, Scotland $(n=14)$ and Wales $(n=6)$ participated. Men alive 18-42 months after a PCa diagnosis (ICD10 ${ }^{16}$ C61) in participating Trusts/Boards were identified from national population-based cancer registries in England, $\mathrm{Nl}$ and Wales. In Scotland, due to privacy restrictions, men were identified through hospital activity data and verified through the cancer registry. There was no age limit for inclusion. Approximately $82 \%$ of eligible men with $\mathrm{PCa}$ across the UK were invited to participate.

The study received the following approvals: Newcastle \& North Tyneside 1 Research Ethics Committee (15/NE/0036), Confidentiality Advisory Group (15/CAG/0110), NHS Scotland Public Benefit and Privacy Panel (0516-0364) and NHS R\&D approval from Wales, Scotland and Northern Ireland. These approvals allowed men to be contacted using details held within cancer registration/hospital activity data. The study protocol can be found at https://bmjopen.bmj.com/content/6/12/e013555. 


\section{Procedures}

Men were sent a postal survey (Appendix p2-22) on behalf of their treating Trust/Board. Men consented by returning completed surveys and declined by not returning them, returning them unanswered or opting out via a free-phone helpline. Up to two reminders were sent to nonresponders. The data collection period differed by nation: England 16/10/2015-21/04/2016; NI 14/06/2016-18/10/2016; Scotland 20/07/2016-01/11/2016; Wales 28/07/2016-09/11/2016). The survey included a range of validated measures, including those defined in the International Consortium on Health Outcome Measurement (ICHOM) minimum outcome dataset $^{14}$ : the Expanded Prostate cancer Index Composite short form (EPIC-26) ${ }^{17}$; items on use of interventions to improve sexual function; and EQ-5D-5L ${ }^{18}$. The survey additionally included questions relating to socio-demographics and treatments received.

Stage at diagnosis was obtained from national cancer registration records. Stage I and II were combined into a 'localised disease' group and compared to stage III and IV separately. An area-based measure of socio-economic deprivation (split into quintiles) was derived using postcode of residence ${ }^{19-22}$. Age, presence of other long-term conditions and treatments received were derived from the survey response data. Age was categorised as $<55,55-64$, $65-74,75-84$, and $\geq 85$ years. Where missing, this was supplemented by cancer registration data (accounting for the lag between diagnosis and survey). Other long-term conditions (Appendix, p19 question 84) were counted and categorised as none, 1, 2, 3, $\geq 4$. Treatments (Appendix, p5-6 question 8) were categorised into single therapies (e.g. surgery alone or external beam radiotherapy [EBRT] alone) or combinations therapies (e.g. EBRT and ADT) (Appendix p23).

A User Advisory Group, including 6 PCa survivors, was chaired by HB (co-investigator and PCa survivor). The group has been involved in all stages of the study from design through to interpretation and dissemination of results.

\section{Outcomes}


Functional outcomes: EPIC-26 measures function across five domains (urinary incontinence, urinary irritation and obstruction, bowel, sexual, vitality/hormone), using 26 items. Domain scores range from $0-100$, with 100 representing best possible function. Mean domain scores were calculated. Where one item in a domain was missing, this was substituted with the mean of the available items, as per the scoring guidance ${ }^{23}$. In addition to mean scores, individual item responses were used to derive the proportion reporting a moderate/big problem (or equivalent), as per Watson et $\mathrm{al}^{24}$.

The ICHOM dataset includes two items assessing use of medications and devices for erectile dysfunction ${ }^{25}$. These were amended to avoid drug/trade names (Appendix, p12 questions 2526). An extra item on use of specialist services to help with sex life was included (Appendix, p13 question 27). The possible response categories were grouped as 'not offered', 'offered but did not want/try it', 'offered but did not help', 'offered and it helped'.

HRQL: EQ-5D-5L records information on five dimensions (mobility, self-care, usual activities, pain/discomfort, anxiety/depression), plus a rating of self-assessed health (SAH) based on "how good or bad your health is today" (valued 0-100, where 100 represents best possible health). The proportion of respondents reporting any problem, regardless of severity, in each dimension separately and across all five dimensions was derived. Mean SAH ratings were calculated.

\section{Statistical analysis}

All men who completed questionnaires were included in analyses. However, as not all men completed every item, records with missing responses were excluded on a question-byquestion basis, thus results refer to the men who responded to that question. Log-linear regression was used to model the continuous outcomes (mean EPIC-26 domain scores and mean EQ-5D SAH score), as this approach provided a better fit to the data than a linear one. Binary logistic regression models were developed for each individual EPIC-26 item (with moderate/big problems, or equivalent, as the outcome) and each EQ-5D dimension (with 
reporting of any problem as the outcome). For each outcome, results were generated by disease stage and treatment group, by adding these variables separately to the models. Each model included adjustment for age (as a linear term), socio-economic deprivation and number of other long-term conditions. Subgroup analyses by age group were adjusted for socioeconomic deprivation and other long-term conditions. Resulting model coefficients were used to predict the mean scores (for the EPIC-26 domains and SAH) and proportions reporting problems (for the individual EPIC-26 items and EQ-5D dimensions) along with 95\% confidence intervals for each stage and treatment group, taking account of the different case-mix profiles of each group. Analysis of the use of interventions for sexual dysfunction was based on the raw survey responses, in order to reflect 'real world' provision of sexual support to men with prostate cancer. Due to the large number of men included in the study, statistical significance can be achieved with only small differences in outcomes, and these may not be clinically relevant. As such, to aid interpretation, results are presented alongside previously estimated minimally important differences (MIDs), where available ${ }^{26-28}$. Analyses were performed using Stata version 15.0 (StataCorp, TX, USA).

\section{Role of the funding source}

The funders of the LAPCD study had no role in the design of the study, the data collection, analysis and interpretation, the writing of the manuscript or the decision to submit for publication. Anonymised study data were available to AD and SW. The corresponding author had full access to the anonymised data and had final responsibility to submit the article for publication.

\section{Results}

A total of 59,990 eligible men were identified; 1,060 (1.8\%) died during the study period, giving a final sample of 58,930 . Of these, 35,823 returned completed questionnaires $(60.8 \%$ response) (Appendix p28). Men aged under 55 (51.8\% response) or over 85 (36.9\% response), from non-white ethnic groups (38.0\% response) and those living in the most socio- 
economically deprived areas (48.3\% response) were less likely to participate (Appendix p24). By stage, response rates were highest in the men diagnosed with stage III cancer $(65.7 \%)$ and lowest in those diagnosed with stage IV disease (58.1\%). Within the completed questionnaires, levels of missing data were generally low e.g. $<3 \%$ missing for EQ-5D (Appendix p25). EPIC-26 items were less well completed and domain scores could not be calculated in $9-18 \%$ of cases. Completion was highest for the sexual function domain and lowest for the urinary irritation domain.

Of the 35,823 men who completed questionnaires, 16,638 (46.4\%) were aged $65-74$ at survey (median 71 years, IQR 67-77) (Table 1). A quarter $(9,408 ; 26.3 \%)$ of the men lived in the least socio-economically deprived areas and 3,620 (10.1\%) lived in the most deprived areas. Most men $(25,418 ; 71.0 \%)$ reported at least one other long-term condition, with $2,563(7.2 \%)$ reporting four or more.

Stage at diagnosis was known for $30,733(85.8 \%)$ of respondents, of whom 19,599 (63.8\%) had stage I or II disease, 7,209 (23.4\%) stage III, and 3,925 (12.8\%) stage IV. Table 1 details the characteristics of each stage group, including those with unknown stage. The men diagnosed with stage IV disease (median age 73 years, IQR 68-79) were older than those with stage I/II disease (median age 71 years, IQR 66-76). The median age of the group with unknown stage was 73 (IQR 67-79). The socio-economic deprivation and long-term condition profiles were similar across the known stage groups, whilst a higher proportion of the group with unknown stage lived in the least socio-economically deprived areas $(p<0.001)$.

The treatments reported by the men are detailed in Table 1. Across the whole cohort, 7,488 (20.9\%) reported receiving combined EBRT and ADT, with a further 7,054 (19.7\%) reporting having surgery alone (Table 1). Of those diagnosed with stage $\mathrm{I} / \mathrm{II}$ disease, $3,986(20.3 \%)$ reported being on a monitoring regime (active surveillance (AS) or watchful waiting) and 4,606 (23.5\%) reported having surgery alone. Most men diagnosed with stage IV cancer were 
receiving $A D T$ at the time of survey, either alone $(1,116 ; 28.4 \%)$ or in combination with EBRT and/or other systemic therapy (chemotherapy, Abiraterone, Enzalutamide) $(1,597 ; 40.7 \%)$.

Mean adjusted EPIC-26 domain scores were high, indicating good function, except for sexual function where scores were much lower $(24.0,95 \% \mathrm{Cl}$ 23.6-24.2) (Table 2). Urinary and bowel function were similar across all disease stages ( $<3$ point difference), whereas vitality/hormone and sexual function were substantially reduced in men with stage III and IV PCa compared to those with localised disease (8-16 point difference for hormone function and 12-17 point difference for sexual function). Men treated surgically reported more urinary incontinence, whilst those on ADT reported worse hormonal and sexual function.

Needing to urinate frequently was the most common urinary symptom (adjusted proportion: $18.6 \%, 95 \% \mathrm{Cl} 18.1-19.0$ reported a moderate/big problem), followed by leaking at least once per day (adjusted proportion: $12.7 \%, 95 \% \mathrm{Cl} 12.3-13.0$ ). There were only small differences in the reporting of urinary symptoms by stage (Figure 1a). Men who underwent surgery reported high levels of urinary incontinence $(23.4 \%, 95 \% \mathrm{Cl} 22.3-24.5$ leaked at least once per day and $31.4 \%, 95 \% \mathrm{Cl} 30.2-32.6$ used one or more pads per day in the surgery alone group) (adjusted proportions: Appendix p26). Problems with urinary frequency and weak stream/incomplete emptying were less of a problem in the 'surgery alone' group than in other treatment groups.

Problems with bowel function were relatively infrequent compared to other domains and varied little by stage of disease (Figure 1a). Bowel urgency was the most common bowel problem (adjusted proportion: $8.8 \%, 95 \% \mathrm{Cl}$ 8.5-9.2 reported a moderate/big problem). Bowel problems were more frequent following EBRT, alone or in combination. For example, 11.4\% (95\% Cl 10.2-12.7) of the 'EBRT alone' group reported moderate/big problems with bowel urgency compared to $4.4 \%(95 \% \mathrm{Cl} 3.9-4.9)$ in the 'surgery alone' group (adjusted proportions: Appendix p26). 
With respect to vitality/hormone function, problems with lack of energy, hot flushes and weight gain were most commonly reported. There were much larger differences in the reporting of these symptoms by stage than was seen for urinary and bowel function (Figure 1a), however, this is related to the treatment received. Men treated with ADT, alone or in combination with other therapy, reported much higher rates of problems with hormonal function and fatigue. For example, $30.7 \%(95 \% \mathrm{Cl} 29.8-31.6)$ of men treated with ADT reported moderate/big problems with hot flushes (compared to $5.4 \%, 95 \% \mathrm{Cl} 5.0-5.8$ in the no-ADT group) and $29.4 \%$ (95\% Cl 28.6-30.3) of men treated with ADT reported problems with lack of energy (compared to $14.7 \%, 95 \% \mathrm{Cl} 14.2-15.3$ in the no-ADT group) (adjusted proportions: Figure $1 \mathrm{~b}$ ). There was a smaller difference in the reporting of depression between the ADT and no-ADT groups (11.4\%, 95\% Cl 10.8-12.0 and 6.6\%, 95\% Cl 6.2-7.0 reporting moderate/big problems).

Problems with sexual function were more common than issues in other domains: poor/very poor erections $(81.5 \%, 95 \% \mathrm{Cl} 81.1-82.0)$, poor/very poor ability to reach orgasm $(76.6 \%, 95 \%$ $\mathrm{Cl} 76.1-77.1)$ and poor/very poor overall sexual function $(81.0 \%, 95 \% \mathrm{Cl} 80.6-81.5)$. In men with localised disease, $75.0 \%(95 \% \mathrm{Cl} 74.3-75.6)$ reported poor/very poor sexual function, as did $90.4 \%$ (95\% Cl 89.7-91.1) of men with stage III and 96.0\% (95\% Cl 95.3-96.6) of men with stage IV cancer (adjusted proportions: Figure 2a). By treatment, just over half of men on AS (51.1\%, 95\% Cl 49.1-53.1) reported poor/very poor overall sexual function, increasing to $83.7 \%(95 \% \mathrm{Cl} 82.8-84.6)$ of men who had surgery alone and $93.6 \%(95 \% \mathrm{Cl} 92.4-94.7)$ receiving ADT alone (adjusted proportions: Appendix p26). By age, just over half (54.5\%, $95 \% \mathrm{Cl} 50.7-58.4)$ of the men aged $<55$ reported poor/very poor sexual function and this increased sharply with age (Figure 2b). A substantial proportion of men (all age groups: $45.2 \%, 95 \% \mathrm{Cl} 44.7-45.8$ ) perceived their (lack of) sexual function to be a moderate/big problem; however, this decreased slightly with age.

Across the cohort, 13,972 men $(41.4 \%)$ reported being offered medications to aid or improve erections, 7,621 (22.6\%) were offered devices to aid erections and 4,894 (14.8\%) were offered specialist services to help with sex life (Appendix p27). Over half $(18,871 ; 55.8 \%)$ were not 
offered any of these interventions. More of the younger men reported having been offered intervention: however, even in the youngest age group (<55 years), 153 men (23.5\%) were not offered medications, $320(48.9 \%)$ were not offered devices and $493(76.0 \%)$ were not offered access to specialist services (Figure 3). By stage, similar proportions of men with stage I/II $(8,678 ; 46.7 \%)$ and stage III $(3,247 ; 47.7 \%)$ disease were offered any of the interventions compared to $957(26.9 \%)$ with stage IV. The proportion of men being offered intervention varied greatly according to the type of treatment received. For example, 5,567 $(80.9 \%)$ of men having surgery alone, $735(62.9 \%)$ of men having brachytherapy alone, 812 (34.5\%) of men having EBRT alone and 523 (18.8\%) of men having ADT alone were offered one of the three interventions.

Amongst men offered any of the three interventions, 5,534 (37.2\%) did not want them or did not try them, 3,546 (23.8\%) found they did not help, and 5,812 (39.0\%) reported at least one of them being helpful (Appendix p27). Of those offered medications, 4,474 (34.2\%) reported them being helpful. Of those offered devices, 2,154 (28.3\%) reported them as helpful. For those offered specialist services, 943 (18.9\%) found them helpful.

The overall mean adjusted SAH score was $76.3(95 \% \mathrm{CI} 76.1-76.5)$ (Table 2). SAH was 5.7 points lower in men with stage IV disease compared to men with localised cancer (mean adjusted scores: 71.7 (95\% Cl 71.1-72.3) and 77.4 (95\% Cl 77.2-77.7) respectively). Men with stage III disease reported a mean adjusted SAH score of 76.3 (95\% CI 75.9-76.7). When looking across the age groups, the difference in SAH between stage I/II and stage IV was greater in the younger men (Figure 4a). A similar pattern was seen when looking at the effect of ADT use by age (Figure $4 b$ ).

Looking at the EQ-5D dimensions, men reported the most problems (of any level) with 'pain/discomfort' (41.7\%, 95\% Cl 41.1-42.2) and fewest problems with 'self-care' $(11.5 \%, 95 \%$ Cl 11.1-11.9) (adjusted proportions: Table 2). Men with stage IV cancer reported more problems in each dimension, and this was highest for 'pain/discomfort' (54.6\%, 95\% Cl 53.0- 
56.3) and 'usual activities' (53.3\%, 95\% Cl 51.6-55.0). Of those with stage IV PCa, $76.5 \%$, $(95 \% \mathrm{Cl} 75.2-77.9)$ reported $\geq 1$ problem on $\mathrm{EQ}-5 \mathrm{D}$, compared to $59.8 \%$ (95\% $\mathrm{Cl} 59.1-60.1)$ of stage I/II and $64.7 \%(95 \% \mathrm{Cl} 63.6-65.9)$ of stage III men. Nearly a quarter of men with stage IV disease reported no problems on any EQ-5D dimension.

\section{Discussion}

To our knowledge, this is the largest population-based patient-reported outcomes study of men with PCa to date. It includes 11,000 men living with locally advanced or metastatic disease, an increasingly prevalent cohort of cancer survivors, frequently excluded from study. The majority of those with stage III disease and approximately $25 \%$ with stage IV disease report good overall HRQL. However, sexual morbidity is high, irrespective of stage of disease, with over half of men reporting they had not been offered intervention to help with this. More than other treatments, men treated with ADT reported poorer outcomes.

Approaching $80 \%$ of the cohort reported poor or very poor sexual function and this was consistently high across the disease stages. A recent study of older men in the general population found that $48 \%$ reported poor sexual function ${ }^{29}$. In this study, $51 \%$ of men on active surveillance reported poor sexual function, which is unlikely to be related to the diagnosis of PCa as they have not received any active treatment. Hence, whilst sexual dysfunction is common in the general population, the levels reported by men treated for PCa are considerably higher. Sexual dysfunction increased with age and is likely partly explained by the normal ageing process. However, the data show that older men are less 'bothered' by their lack of sexual function. In the youngest men, around $50 \%$ reported poor function and the same proportion reported it to be a problem. In the older men, over $80 \%$ reported poor function but they were less likely to be 'bothered' by it. Overall, $56 \%$ reported not being offered access to medications, devices or specialist services to improve sexual function, and only $40 \%$ of those offered help found it to be beneficial. Access to these interventions varied by age and by treatment received. Further analysis of these data is needed to look at this variation in 
more detail and to understand which groups of men are finding the interventions helpful. However, to our knowledge, this extent of failure to receive support has not previously been described. This intelligence would suggest clinical services need to proactively address this and ensure that sexual support is routinely offered to all men. However, it must be acknowledged that not all men see their lack of sexual function as a problem and some will not want intervention to address this.

Overall levels of urinary and bowel problems in men with PCa are relatively low; however, there are subgroups with increased levels of dysfunction. For example, men treated surgically reported higher levels of urinary incontinence with $30 \%$ reporting using pads daily, a finding which supports previous research ${ }^{5,8}$. These men are between 18 and 42 months postdiagnosis and there may be some recovery in function with longer follow-up ${ }^{5}$.

In general, those with stage III and IV disease reported a higher level of problems, but in many cases these differences were small and were less than previously estimated MIDs for urinary and bowel function ${ }^{28}$. Larger impacts on sexual function, hormonal function, fatigue and depression were seen and will, in part, be driven by treatment with ADT. The majority of men with stage III or IV PCa will be on long-term or indefinite ADT. There may be some recovery in those who stop ADT, with a corresponding reduction in symptoms, but testosterone levels may never recover to pre-treatment levels. Longer-term follow-up of men would be required to assess recovery of sexual function, levels of fatigue and other ADT-related effects. The results suggest that clinicians should pursue treatment approaches that preserve testosterone function when possible and minimise ADT use. Steps to reduce ADT-related morbidity might include wider use of intermittent ADT (versus continuous use), the avoidance of unnecessary ADT (i.e. for non-metastatic disease) and the use of shorter neoadjuvant courses (reduced from 3 years to 1 year).

Despite the problems with sexual dysfunction, urinary difficulties and hormonal issues in some groups, this cohort of men living with and beyond the diagnosis of PCa report similar SAH to 
men in the general population ${ }^{29,30}$ (Table 3). Differences in SAH amongst the overall LAPCD and general population samples are small, less than 3 points, with minimally important differences in EQ-5D SAH ratings having previously been estimated at 7 points ${ }^{26,27}$. This apparent "resilience" of men with PCa may be accounted for by the "Gap Hypothesis" of quality of life, with the diagnosis of a life-threatening illness and subsequent experience of undergoing treatment leading to re-calibration of expectations and values ${ }^{31}$.

Overall the SAH of men with stage III disease is not markedly different from those with localised disease or UK general population surveys. Whilst scores from those with stage IV disease are 6 points lower than those with localised disease, this may not equate to a clinically meaningful difference. A quarter of men with stage IV PCa report no problems in any EQ-5D domain. Not all men with Stage IV PCa experience similar clinical trajectories, with some living for prolonged periods and others living significantly shorter periods from diagnosis. Subgroups of men, such those with oligometastatic disease, may experience few problems whilst others experience diminished HRQL. This study did not capture the detailed clinical information needed to investigate subtypes of disease. The absence of other at-scale studies of the outcomes of men living with stage III and IV disease prevent comparison with other studies. Further investigation into the outcomes of men living with metastatic disease is required, particularly over a longer time period, as many will only develop symptoms a number of years after diagnosis.

Through whole population sampling, potential recruitment or clinical trial intervention bias has been avoided. In addition, all disease stages and treatments have been included, adding important new data on men living with and beyond diagnoses of advanced disease who have been largely omitted from previous quality of life outcome studies. Utilisation of a standardised set of accepted outcome measures enables future international benchmarking. Data collection at this scale, from all centres in NI, Scotland and Wales and 111 of 136 NHS Trusts in England, has allowed us to produce datasets for individual Trusts, Cancer Alliances and regional health boards. Internet-based tools will be made available to support service 
improvement, and in parallel, a public-facing electronic tool will provide an information and decision-making resource for men and their families, through identification of expected outcomes based on robust unselected data.

Four NHS Trusts were excluded from the study as they were participating in an overlapping programme ${ }^{32}$. A further 21 Trusts did not participate. Several of these declined because they were already participating in other local PROMs studies and were concerned about questionnaire fatigue. The remaining Trusts did not respond to the multiple invitations to take part.

The response rate of $61 \%$ is comparable to a similar survey of colorectal cancer survivors in England $(63 \%)^{13}$. Comparison of rates with other PCa trials and cohort studies is difficult due to different identification and recruitment methods. Our response rate is reported without exclusion or screening of eligible individuals. Non-respondents were more likely to be older, Black, Asian or minority ethnic and live in more socio-economically deprived areas. These are groups who may be expected to potentially experience poorer HRQL. Variation in response rate by stage was identified, with those with stage III disease having the highest response rates and those with stage IV disease at diagnosis the lowest. We do not know if patients with worse health status were less likely to respond. Data completeness was high for the majority of questions. Records with missing data were excluded from analysis, which assumes that those who did not respond to the question have similar outcomes to those who did. This assumption cannot be validated using the available data. Men were less likely to avoid questions on sexual function than they were for some of the other domains, which is perhaps counter-intuitive but could indicate a real concern in this otherwise healthy-feeling group.

Staging information was taken from national cancer registration data at diagnosis and was available for $86 \%$ of respondents. The cancer registry uses a variety of data sources, including pathology reports and treatment databases, to capture stage information. Some groups of 
men are less likely to appear in a treatment or pathology dataset near the time of diagnosis (for instance, those on watchful waiting are less likely to have a biopsy). At the time when men in this study were diagnosed, there was less access to multi-disciplinary team systems to capture staging information, though this has now improved. Cancer registries routinely derive an area-based measure of socio-economic deprivation using patient postcode and completeness of this is high ( $2 \%$ missing in our study). It was decided to use this measure rather than add additional items to an already long questionnaire. Treatment information was self-reported, due to limited data in cancer registries on types of monitoring and difficulties in capturing hormone therapies administered through primary care prescriptions (Public Health England, Personal Communication). However, some respondents had difficulty reporting the treatments they received (e.g. distinguishing between types of radiotherapy) and these groups had to be excluded from some analyses.

Most men living 18-42 months after diagnosis of PCa can expect to experience as good HRQL as men in the general population. Those diagnosed with locally advanced and metastatic disease do not report markedly different HRQL outcomes to those diagnosed with localised disease, although significant problems with hormonal function and fatigue are reported as a result of ADT. However, it should be recognised that this study covers a limited window of time and HRQL in those with metastatic disease may deteriorate over a longer time period. Sexual dysfunction is common across all disease stages, with notably poor provision of sexual support. Our results suggest that there are subgroups of men who would benefit from service improvements around sexual rehabilitation and measures to reduce the impact of ADT. This study shows that outcomes for men with PCa are more strongly linked with the treatments received than disease stage itself, although clearly the two are intertwined. These results allow clinicians to present very positive goals for quality of survival $18-42$ months after diagnosis, including for a substantial proportion of men with metastatic disease. 


\section{Acknowledgements}

The authors thank all the men who completed surveys. We acknowledge the following people for their contribution to the development and running of the study: Heather Kinnear, Victoria Cairnduff, Conan Donnelly, Fraser Munro, Linda Roberts, Dawn Allen, Janet Warlow, the User Advisory Group, Clinical \& Scientific Advisory Group and Picker Institute Europe. This study is based in part on information collected and quality assured by the cancer registries in each nation. Their work uses data provided by patients and collected by health services as part of their care and support.

\section{Ethical approval}

The study received the following approvals: Newcastle \& North Tyneside 1 Research Ethics Committee (15/NE/0036), Confidentiality Advisory Group (15/CAG/0110), NHS Scotland Public Benefit and Privacy Panel (0516-0364) and NHS R\&D approval from Wales, Scotland and Northern Ireland.

\section{Authors' contributions}

$A G$ and AWG are co-Principal Investigators and designed the study together with coinvestigators AD, PW, LH, PS, EW, RW, PK and HB. RM, MA, TK and OS managed the study and data collection. AD and SW analysed the data. JC, WC, MM, LS, DW, EM, GV and DH are members of the Clinical \& Scientific Advisory Group (chaired by PS) which provided study oversight and advised on interpretation of the data. DD, DB, EMcN and DH advised on study design, data collection and interpretation of data from the devolved nations. AD wrote the initial draft of the paper. All authors contributed to critically revising the paper and approved the final version.

\section{Declaration of interests}

AWG reports grants from Candlelighters, Macmillan Cancer Support, NIHR, and Yorkshire Cancer Research outside the submitted work. JC reports personal fees from Steba Biotech (ad board), outside the submitted work; GV reports grants from NIHR, grants from Yorkshire 
Cancer Research, grants from Cancer Research UK, personal fees from Roche, personal fees from Novartis, personal fees and non-financial support from Eisai outside the submitted work, MM reports personal fees from Janssen and Endocyte outside the submitted work. All other authors declared no conflicts of interest. 


\section{References}

1. Cancer Research UK. Prostate cancer survival statistics.

http://www.cancerresearchuk.org/health-professional/cancer-statistics/statistics-by-cancertype/prostate-cancer/survival (last accessed 03/10/2018).

2. National Cancer Registration and Analysis Service. Cancer Prevalence in England: 21 year prevalence by demographic and geographic measures.

http://www.ncin.org.uk/local cancer intelligence/tcst (last accessed 03/10/2018).

3. National Cancer Institute: Survival Epidemiology and End Results Program. Cancer Stat Facts: Prostate Cancer. 2017. https://seer.cancer.gov/statfacts/html/prost.html (last accessed 03/10/2018).

4. Glaser AW, Corner JL. Prostate Cancer Outcomes: The Three Questions. European Urology 2015; 67(3): 357-8.

5. Donovan JL, Hamdy FC, Lane JA, et al. Patient-Reported Outcomes after Monitoring, Surgery, or Radiotherapy for Prostate Cancer. New England Journal of Medicine 2016; 375(15): 1425-37.

6. Resnick MJ, Koyama T, Fan K-H, et al. Long-Term Functional Outcomes after Treatment for Localized Prostate Cancer. New England Journal of Medicine 2013; 368(5): 436-45.

7. Johansson E, Steineck G, Holmberg L, et al. Long-term quality-of-life outcomes after radical prostatectomy or watchful waiting: the Scandinavian Prostate Cancer Group-4 randomised trial. The Lancet Oncology 2011; 12(9): 891-9.

8. Barocas DA, Alvarez J, Resnick MJ, et al. Association between radiation therapy, surgery, or observation for localized prostate cancer and patient-reported outcomes after 3 years. JAMA 2017; 317(11): 1126-40.

9. Wallis CJD, Glaser A, Hu JC, et al. Survival and complications following surgery and radiation for localized prostate cancer: An international collaborative review. Eur Urol 2018; 73(1): 11-20. 
10. Torvinen S, Farkkila N, Sintonen H, Saarto T, Roine RP, Taari K. Health-related quality of life in prostate cancer. Acta Oncol 2013; 52(6): 1094-101.

11. Rosenfeld B, Roth AJ, Gandhi S, Penson D. Differences in health-related quality of life of prostate cancer patients based on stage of cancer. Psychooncology 2004; 13(11): 800-7.

12. Adamowicz K. Assessment of quality of life in advanced, metastatic prostate cancer: an overview of randomized phase III trials. Qual Life Res 2017; 26(4): 813-22.

13. Downing A, Morris EJ, Richards M, et al. Health-related quality of life after colorectal cancer in England: a patient-reported outcomes study of individuals 12 to 36 months after diagnosis. J Clin Oncol 2015; 33(6): 616-24.

14. Martin NE, Massey L, Stowell C, et al. Defining a standard set of patient-centered outcomes for men with localized prostate cancer. Eur Urol 2015; 67(3): 460-7.

15. Downing $A$, Wright $P$, Wagland $R$, et al. Life after prostate cancer diagnosis: protocol for a UK-wide patient-reported outcomes study. BMJ Open 2016; 6(12).

16. World Health Organisation. ICD10 International Statistical Classification of Disease and Related Health Problems. World Health Organisation, Geneva. 2004.

17. Wei JT, Dunn RL, Litwin MS, Sandler HM, Sanda MG. Development and validation of the expanded prostate cancer index composite (EPIC) for comprehensive assessment of health-related quality of life in men with prostate cancer. Urology 2000; 56(6): 899-905.

18. Herdman M, Gudex C, Lloyd A, et al. Development and preliminary testing of the new five-level version of EQ-5D (EQ-5D-5L). Qual Life Res 2011; 20(10): 1727-36.

19. Department for Communities and Local Government. English Indices of Multiple Deprivation 2010. https://www.gov.uk/government/statistics/english-indices-of-deprivation2010 (last accessed 03/10/2018).

20. Welsh Government. Welsh Index of Multiple Deprivation. http://wimd.wales.gov.uk/?lang=en (last accessed 03/10/2018). 
21. ISD Scotland. The Scottish Index of Multiple Deprivation (SIMD).

http://www.isdscotland.org/Products-and-Services/GPD-Support/Deprivation/SIMD/ (last accessed 03/10/2018).

22. Northern Ireland Statistics and Research Agency. NI Multiple Deprivation Measure. https://www.nisra.gov.uk/statistics/deprivation/northern-ireland-multiple-deprivation-measure2010-nimdm2010 (last accessed 03/10/2018).

23. Scoring instructions for the Expanded Prostate cancer Index Composite short form (EPIC-26). University of Michigan; 2002.

24. Watson E, Shinkins B, Frith E, et al. Symptoms, unmet needs, psychological wellbeing and health status in survivors of prostate cancer: implications for redesigning followup. BJU Int 2015; 116(6B): E10-9.

25. Miller DC, Wei JT, Dunn RL, et al. Use of medications or devices for erectile dysfunction among long-term prostate cancer treatment survivors: potential influence of sexual motivation and/or indifference. Urology 2006; 68(1): 166-71.

26. Pickard A, Neary M, Cella D. Estimation of minimally important differences in EQ-5D utility and VAS scores in cancer. Health Qual Life Outcomes 2007; 5: 70.

27. Pickard A, Neary M, Cella D. Estimation of minimally important differences in EQ-5D utility and VAS scores in cancer. Health Qual Life Outcomes 2010; 8: 4.

28. Skolarus TA, Dunn RL, Sanda MG, et al. Minimally Important Difference for the Expanded Prostate Cancer Index Composite Short Form. Urology 2015; 85(1): 101-6.

29. Donnelly D, Donnelly C, Kearney T, et al. Urinary, bowel and sexual health in older men from Northern Ireland. BJU Int 2017; doi: 10.1111/bju.14182.

30. NHS Digital. Health Survey for England - 2012. https://digital.nhs.uk/data-andinformation/publications/statistical/health-survey-for-england/health-survey-for-england-2012 (last accessed 03/10/2018).

31. Calman K. Quality of life in cancer patients - an hypothesis. J Med Ethics 1984; 10(3): $124-7$. 
32. University of Southampton. Research project: Development, implementation and evaluation of the True NTH Supported Self Management and Follow Up Care Programme. 2018. http://www.southampton.ac.uk/healthsciences/research/projects/development-impltrue-nth.page (last accessed 03/10/2018). 
Table 1: Characteristics of the study sample split by stage at diagnosis

\begin{tabular}{|c|c|c|c|c|c|c|c|c|c|c|c|}
\hline & & \multicolumn{2}{|c|}{ All men } & \multicolumn{2}{|c|}{ Stage I/II } & \multicolumn{2}{|c|}{ Stage III } & \multicolumn{2}{|c|}{ Stage IV } & \multicolumn{2}{|c|}{ Stage unknown } \\
\hline & & $\mathbf{n}$ & $\%$ & $\mathbf{n}$ & $\%$ & $\mathbf{n}$ & $\%$ & n & $\%$ & $n$ & $\%$ \\
\hline Total & & 35,823 & 100.0 & 19,599 & 54.7 & 7,209 & 20.1 & 3,925 & 11.0 & 5,090 & 14.2 \\
\hline \multirow{11}{*}{ Treatment } & Active surveillance & 2,928 & 8.2 & 2,320 & 11.8 & 0 & 0.0 & 0 & 0.0 & 457 & 9.0 \\
\hline & Watchful waiting & 2,292 & 6.4 & 1,666 & 8.5 & 182 & 2.5 & 164 & 4.2 & 993 & 19.5 \\
\hline & Brachytherapy alone & 1,208 & 3.4 & 940 & 4.8 & 62 & 0.9 & 13 & 0.3 & 294 & 5.8 \\
\hline & Surgery alone & 7,054 & 19.7 & 4,606 & 23.5 & 1,323 & 18.4 & 132 & 3.4 & 193 & 3.8 \\
\hline & Surgery + EBRT/ADT & 2,349 & 6.6 & 853 & 4.4 & 801 & 11.1 & 339 & 8.6 & 548 & 10.8 \\
\hline & EBRT alone & 2,536 & 7.1 & 1,533 & 7.8 & 573 & 7.9 & 136 & 3.5 & 431 & 8.5 \\
\hline & EBRT + ADT & 7,488 & 20.9 & 3,688 & 18.8 & 2,359 & 32.7 & 658 & 16.8 & 783 & 15.4 \\
\hline & ADT alone & 3,116 & 8.7 & 965 & 4.9 & 487 & 6.8 & 1,116 & 28.4 & 356 & 7.0 \\
\hline & Systemic + ADT & 630 & 1.8 & 71 & 0.4 & 37 & 0.5 & 450 & 11.5 & 72 & 1.4 \\
\hline & Systemic + EBRT (+/- ADT) & 513 & 1.4 & 84 & 0.4 & 128 & 1.8 & 237 & 6.0 & 64 & 1.3 \\
\hline & Other treatment groups & 5,709 & 15.9 & 2873 & 14.7 & 1257 & 17.4 & 680 & 17.3 & 899 & 17.7 \\
\hline \multirow{6}{*}{ Age at survey } & $<55$ years & 661 & 1.8 & 447 & 2.3 & 92 & 1.3 & 45 & 1.1 & 77 & 1.5 \\
\hline & $55-64$ years & 5,594 & 15.6 & 3,366 & 17.2 & 1,026 & 14.2 & 473 & 12.1 & 729 & 14.3 \\
\hline & $65-74$ years & 16,638 & 46.4 & 9,420 & 48.1 & 3,406 & 47.2 & 1,712 & 43.6 & 2,100 & 41.3 \\
\hline & $75-84$ years & 11,082 & 30.9 & 5,670 & 28.9 & 2,391 & 33.2 & 1,326 & 33.8 & 1,695 & 33.3 \\
\hline & $85+$ years & 1,842 & 5.1 & 696 & 3.6 & 294 & 4.1 & 369 & 9.4 & 483 & 9.5 \\
\hline & Unknown & 6 & 0.02 & 0 & 0.0 & 0 & 0.0 & 0 & 0.0 & 6 & 0.1 \\
\hline \multirow{6}{*}{$\begin{array}{l}\text { Socio-economic } \\
\text { deprivation } \\
\text { quintile }\end{array}$} & 1 - least deprived & 9,408 & 26.3 & 5,128 & 26.2 & 1,802 & 25.0 & 962 & 24.5 & 1,516 & 29.8 \\
\hline & 2 & 9,289 & 25.9 & 5,186 & 26.5 & 1,889 & 26.2 & 1,000 & 25.5 & 1,241 & 24.4 \\
\hline & 3 & 7,381 & 20.6 & 4,082 & 20.8 & 1,504 & 20.9 & 869 & 22.1 & 926 & 18.2 \\
\hline & 4 & 5,266 & 14.7 & 2,846 & 14.5 & 1,084 & 15.0 & 596 & 15.2 & 740 & 14.5 \\
\hline & 5 - most deprived & 3,620 & 10.1 & 1,955 & 10.0 & 786 & 10.9 & 421 & 10.7 & 458 & 9.0 \\
\hline & Unknown & 859 & 2.4 & 402 & 2.1 & 144 & 2.0 & 77 & 2.0 & 236 & 4.6 \\
\hline \multirow{5}{*}{$\begin{array}{l}\text { No. of other } \\
\text { long-term } \\
\text { conditions }\end{array}$} & 0 & 10,405 & 29.0 & 5,740 & 29.3 & 2,087 & 28.9 & 1,131 & 28.8 & 1,447 & 28.4 \\
\hline & 1 & 12,527 & 35.0 & 6,910 & 35.3 & 2,594 & 36.0 & 1,316 & 33.5 & 1,707 & 33.5 \\
\hline & 2 & 7,154 & 20.0 & 3,827 & 19.5 & 1,432 & 19.9 & 807 & 20.6 & 1,088 & 21.4 \\
\hline & 3 & 3,174 & 8.9 & 1,708 & 8.7 & 605 & 8.4 & 391 & 10.0 & 470 & 9.2 \\
\hline & $\geq 4$ & 2,563 & 7.2 & 1,414 & 7.2 & 491 & 6.8 & 280 & 7.1 & 378 & 7.4 \\
\hline
\end{tabular}

EBRT: External beam radiotherapy; ADT: Androgen deprivation therapy; Systemic therapy includes chemotherapy/Abiraterone/Enzalutamide. 
Table 2: Functional and HRQL outcomes in men diagnosed with prostate cancer 18-42 months previously

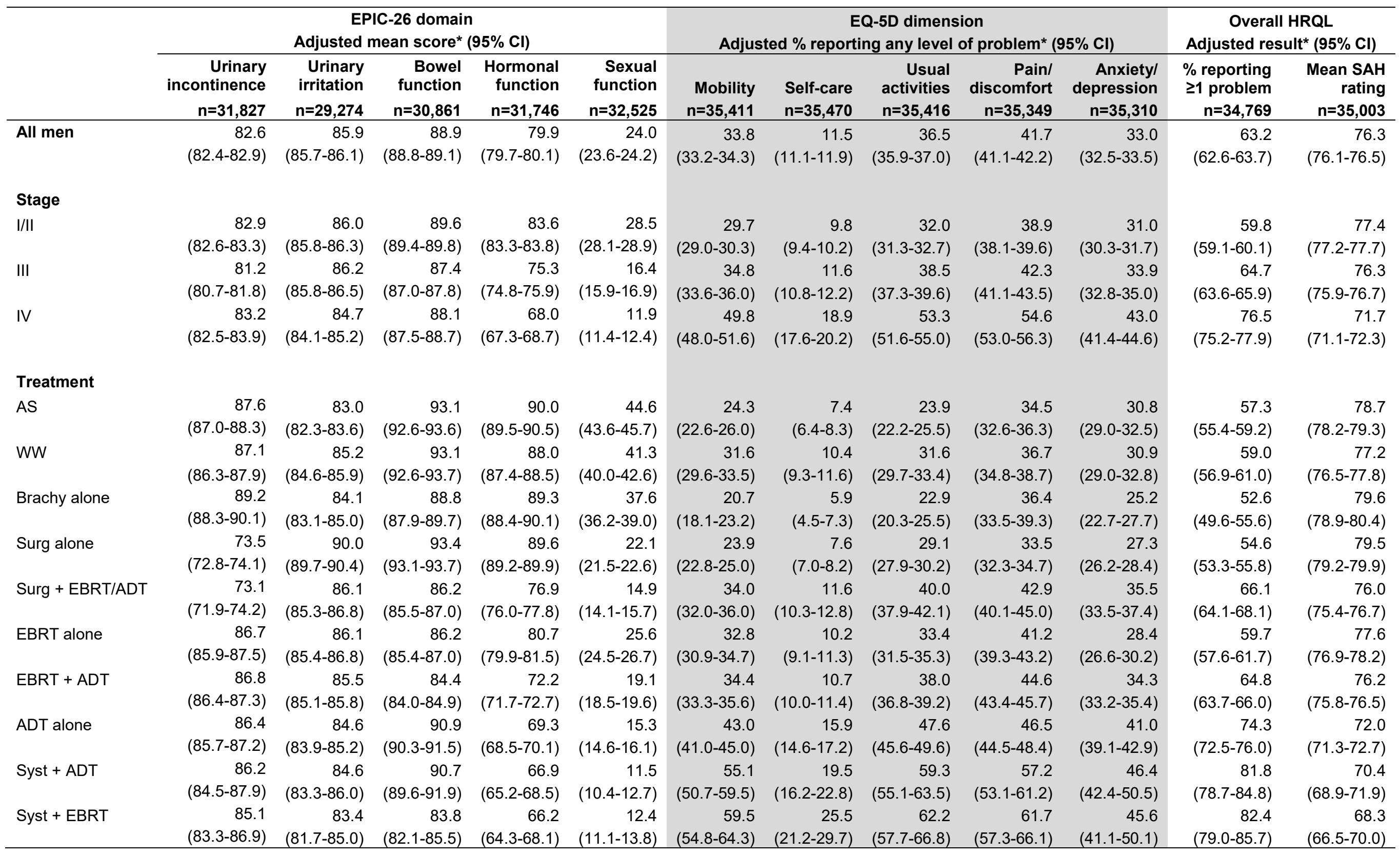

${ }^{*}$ Adjusted for age at survey, socio-economic deprivation and number of other long-term conditions 
For EPIC-26 scores and SAH ratings, 100=best possible function/health

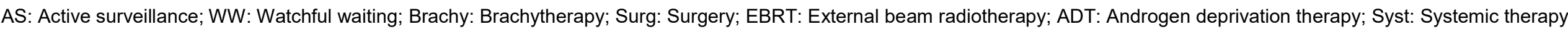
(Chemotherapy/Abiraterone/Enzalutamide); SAH: Self-assessed health.

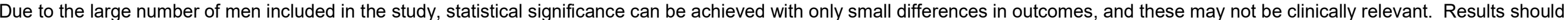

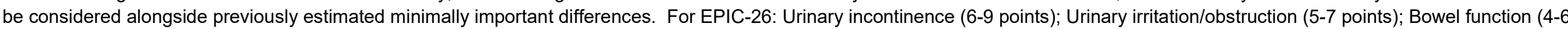
points); Vitality/hormone function (4-6 points); Sexual function (10-12 points). For EQ-5D Self-assessed health (7 points). 
Table 3: Comparison of self-assessed health ratings in the LAPCD cohort and general population surveys (men aged 60 and over)

\begin{tabular}{lrr}
\hline & $\boldsymbol{n}$ & Mean SAH \\
\hline LAPCD & & \\
Stage I/II & 18,055 & 77.8 \\
Stage III & 6,792 & 76.6 \\
Stage IV & 3,759 & 71.7 \\
Overall & 33,370 & 76.5 \\
& & \\
General population & & \\
Northern Ireland, 2016 & \\
Health Survey for England, 2012 & 1,016 & 77.2 \\
\hline
\end{tabular}

SAH: Self-assessed health

${ }^{1}$ Northern Ireland General population survey (Donnelly et al. Urinary, bowel and sexual health in older men from Northern Ireland. BJU Int 2018. doi: 10.1111/bju.14182).

${ }^{2}$ Health Survey for England 2012 (NHS Digital. Available from https://digital.nhs.uk/data-and-

information/publications/statistical/health-survey-for-england/health-survey-for-england-2012). 
Figure 1: Urinary, bowel and vitality/hormone function in men diagnosed with prostate cancer 18-42 months previously

a) Moderate/big problems with urinary, bowel and hormone function by stage

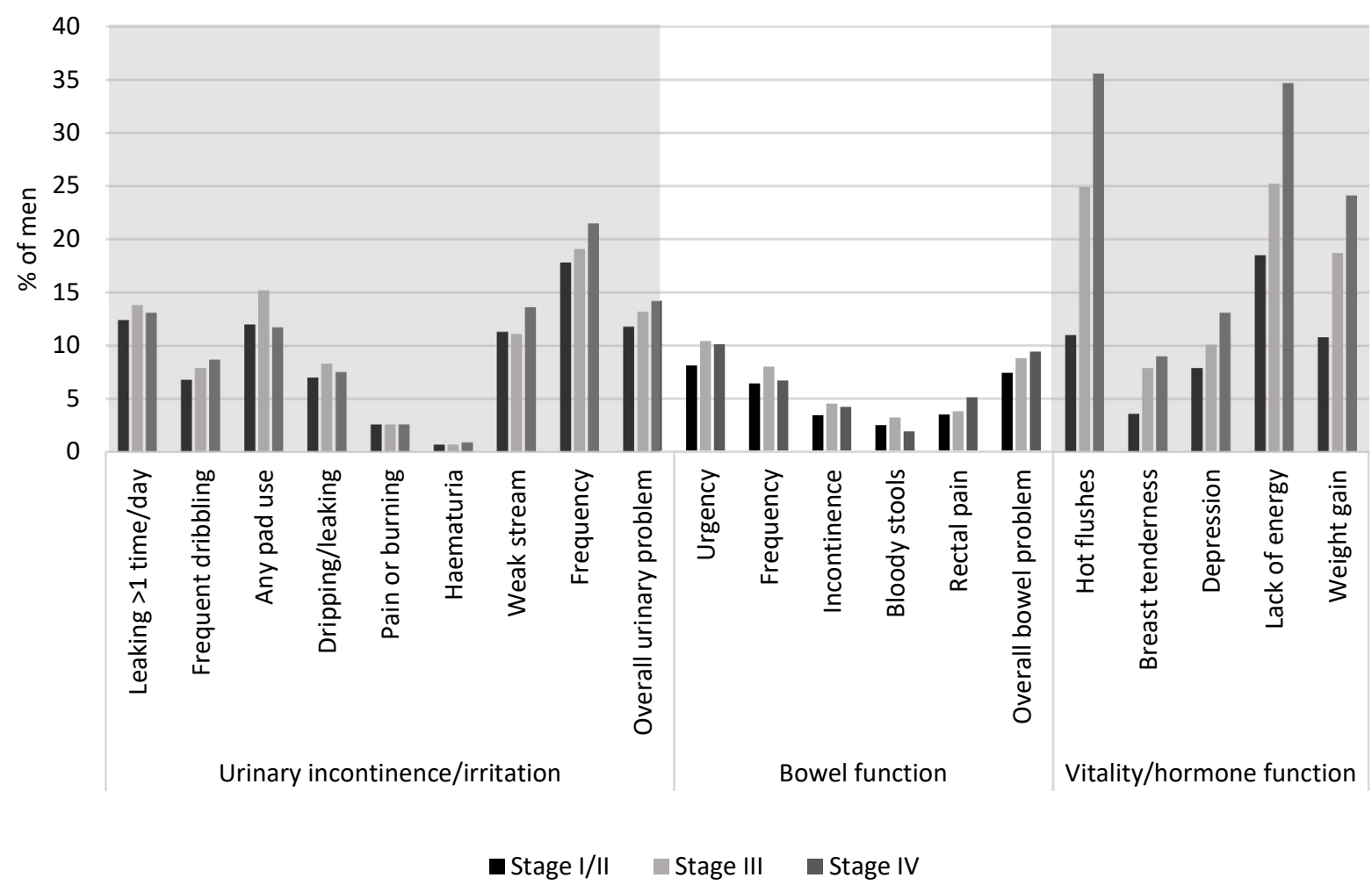

b) Moderate/big problems with hormone function by ADT use

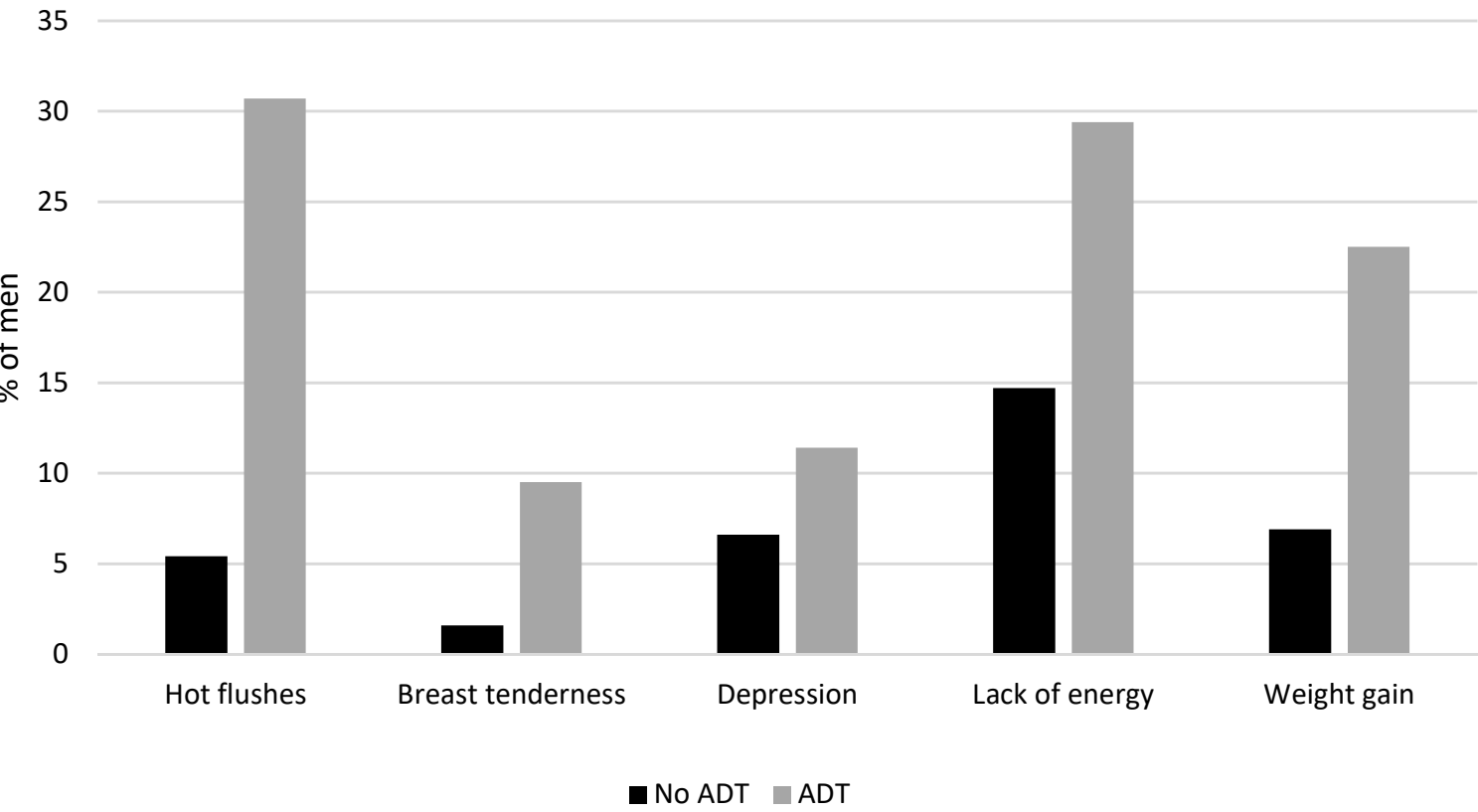

Figures represent predicted adjusted proportions (adjusted for age, socio-economic deprivation and no. of other longterm conditions)

ADT: Androgen deprivation therapy 
Figure 2: Sexual function in men diagnosed with prostate cancer 18-42 months previously

a) Moderate/big problems with sexual function by stage

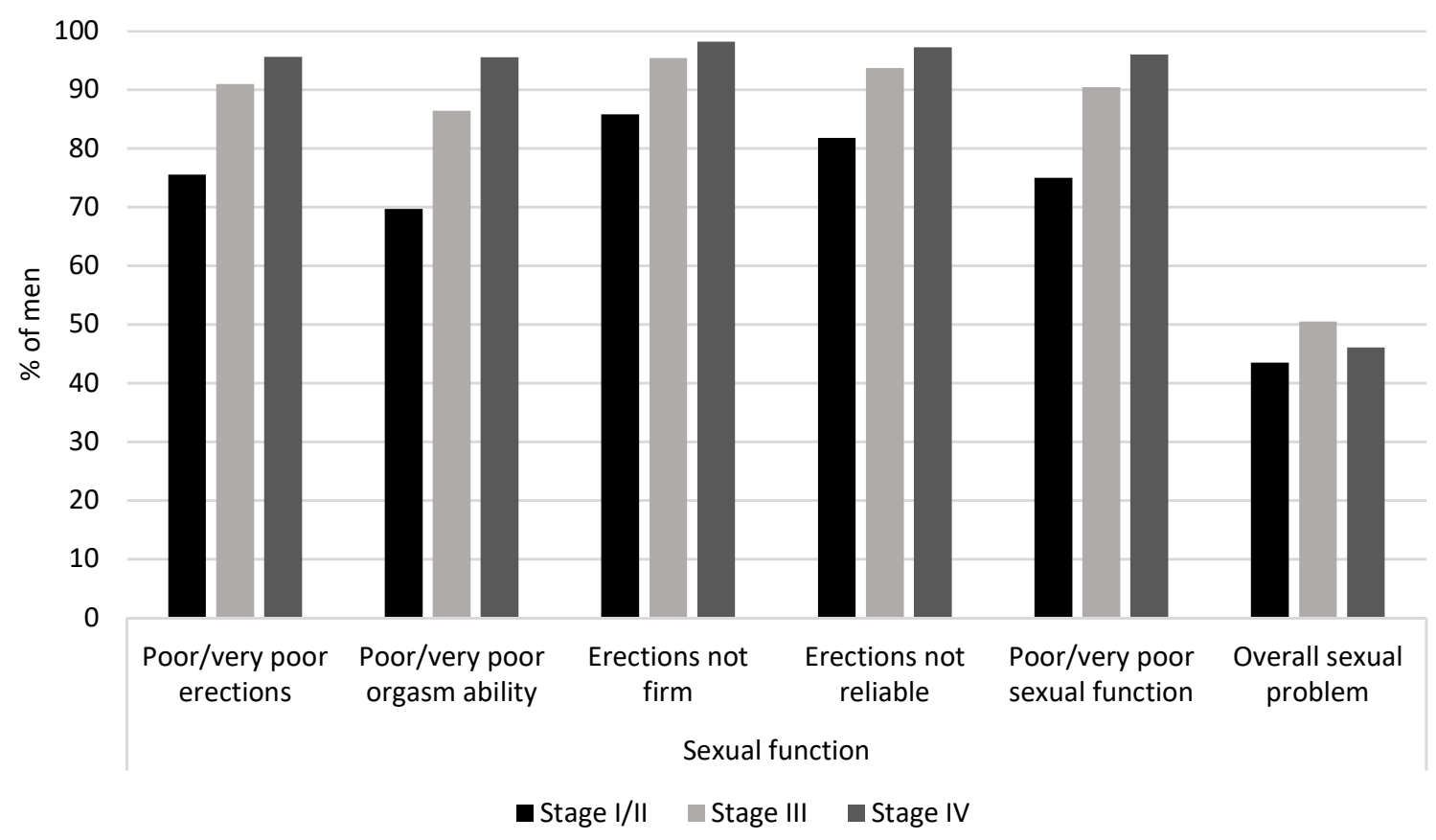

Figure 2a represents predicted adjusted proportions (adjusted for age, socio-economic deprivation and no. of other long-term conditions)

b) Sexual function and level of overall sexual problem by age

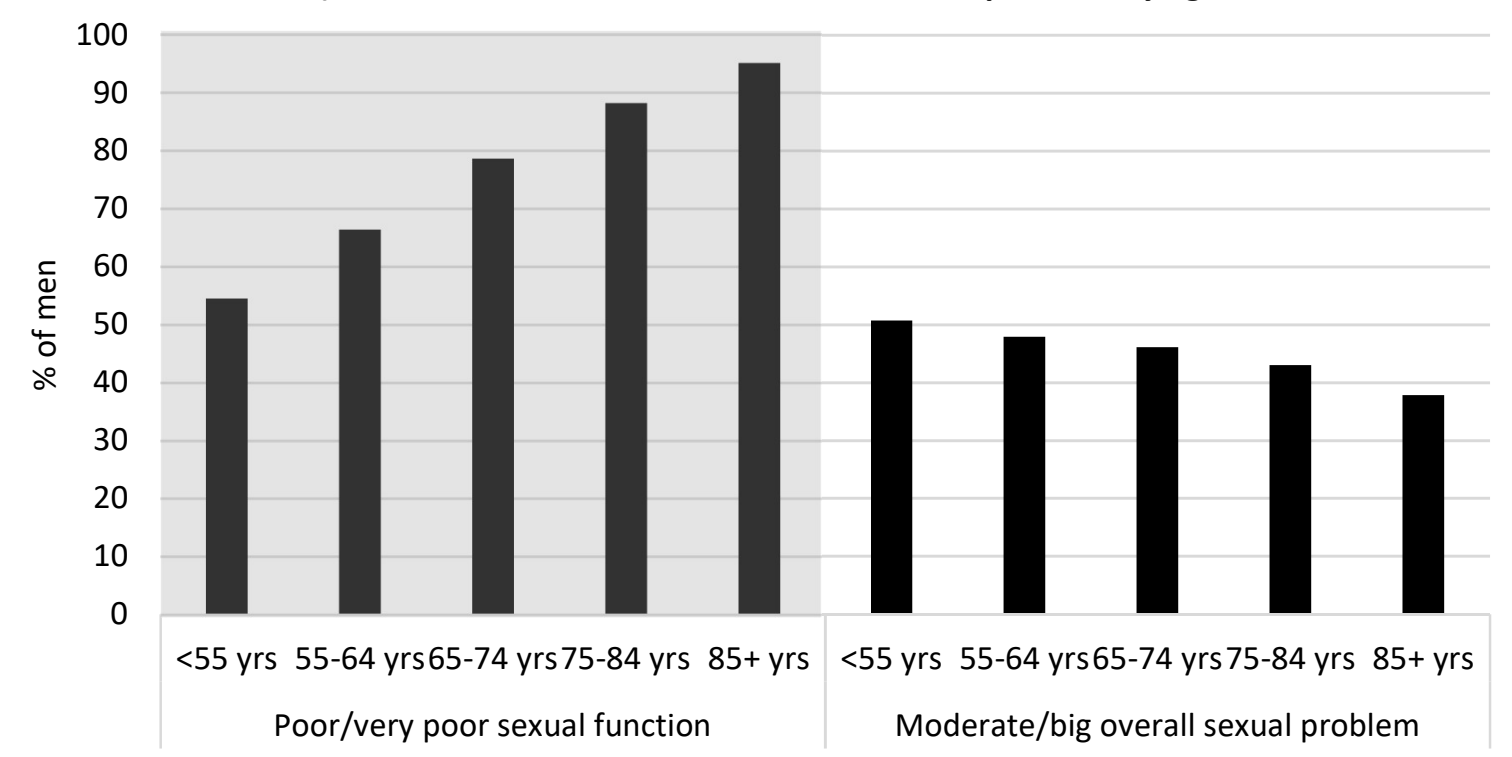

Figure $2 \mathrm{~b}$ represents predicted adjusted proportions (adjusted for socio-economic deprivation and no. of other longterm conditions) 
Figure 3: Use of interventions to improve sexual function by men diagnosed with prostate cancer 18-42 months previously

a) Any intervention: Medications, devices or services

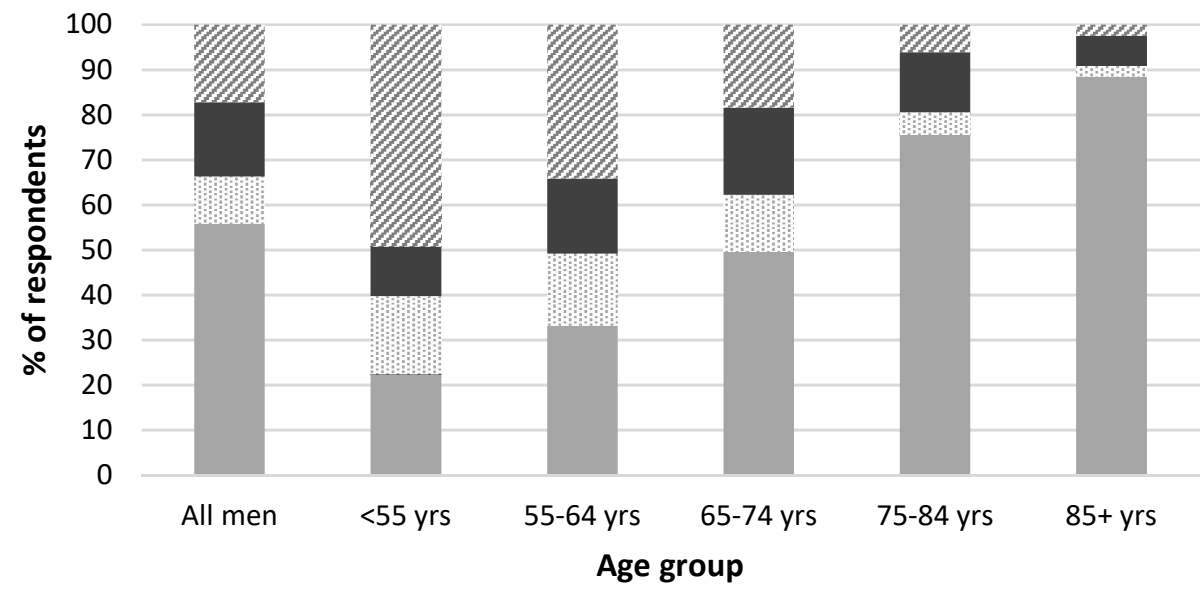

Not offered

Offered but did not help

- Offered but did not want/try it

c) Devices to aid or improve erections

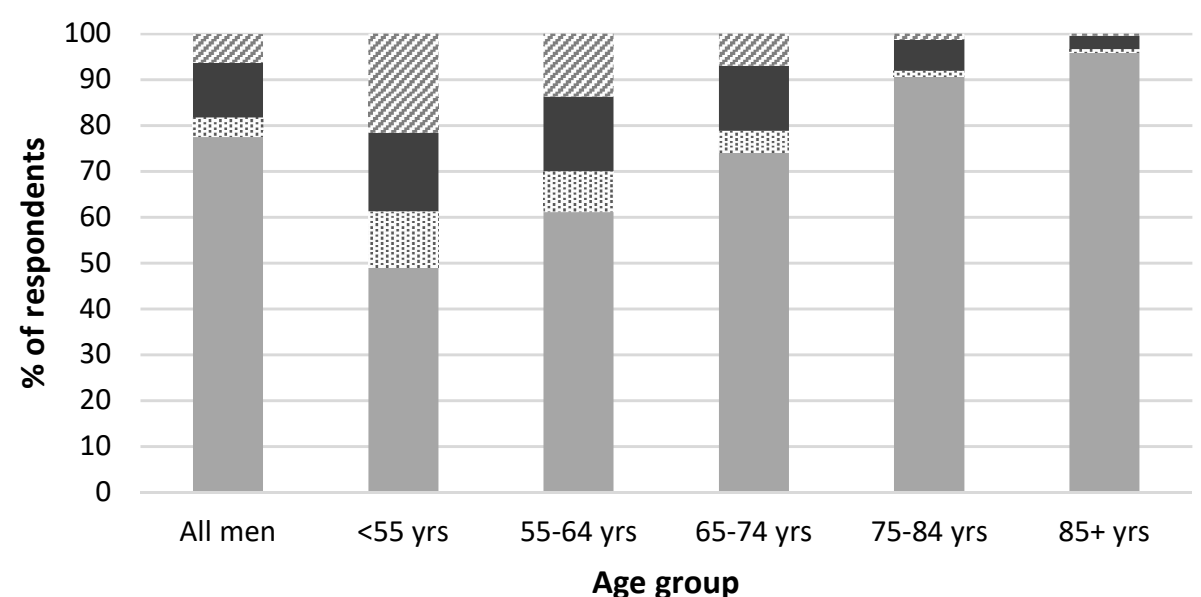

Not offered

Offered but did not help

- Offered but did not want/try it $\quad \forall$ Offered and it helped b) Medications to aid or improve erections

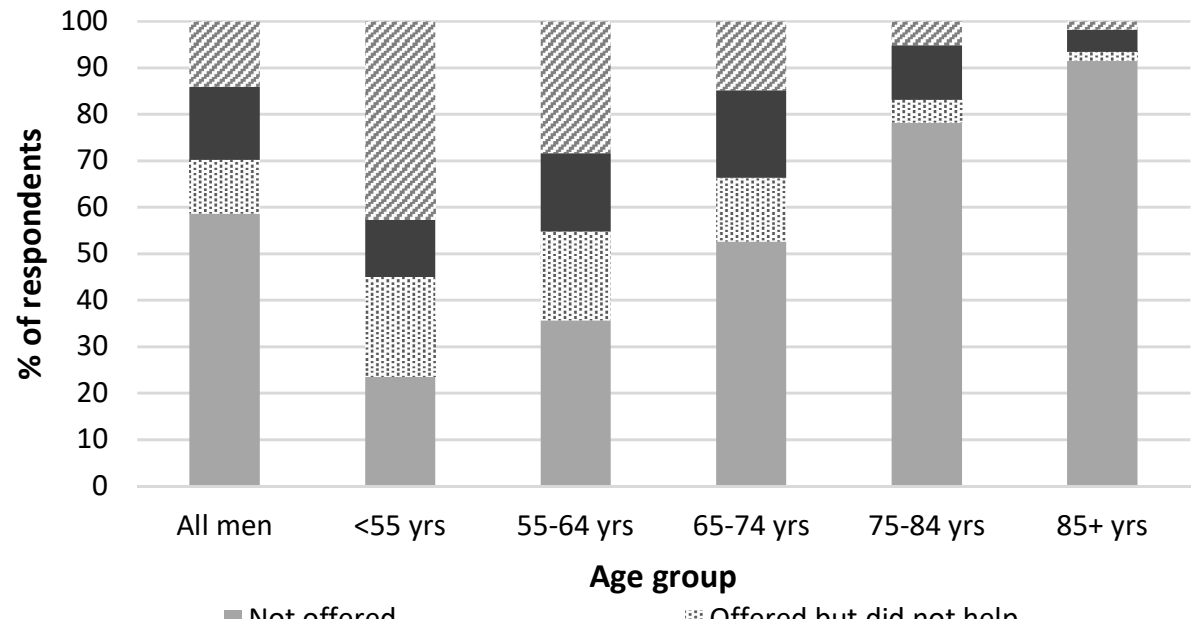

Offered but did not help

- Offered but did not want/try it $\quad \forall$ Offered and it helped

d) Specialist services to improve sex life

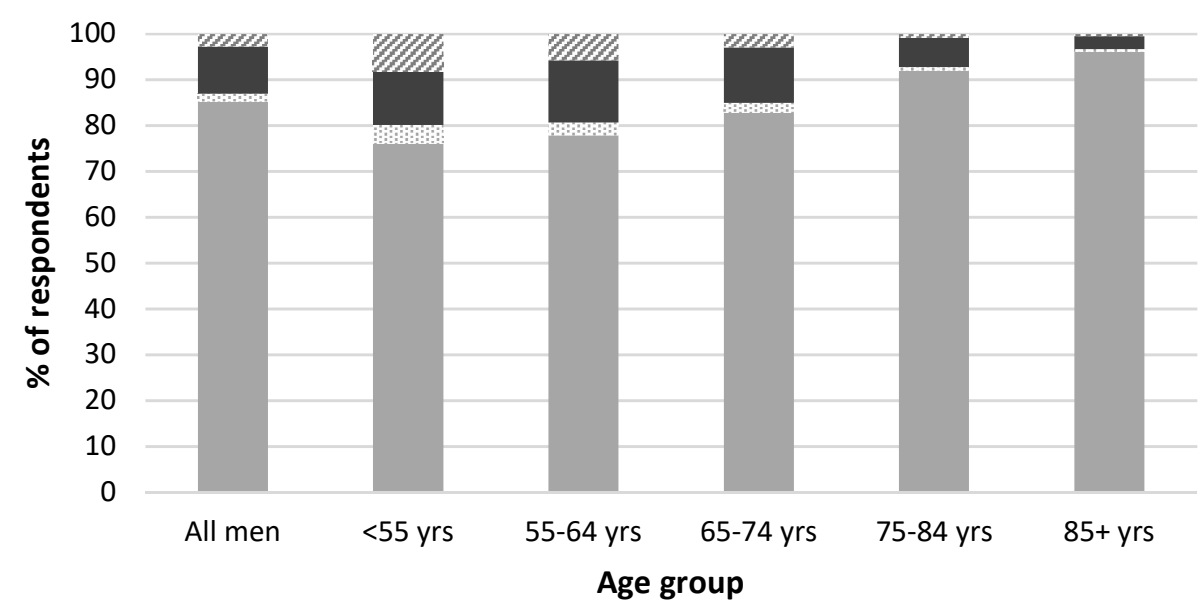

Not offered Offered but did not help

- Offered but did not want/try it $\approx$ Offered and it helped 
Figures represent unadjusted proportions 
Figure 4: Self-assessed health ratings in men diagnosed with prostate cancer 18-42 months previously

a) Mean self-assessed health rating by stage and age group

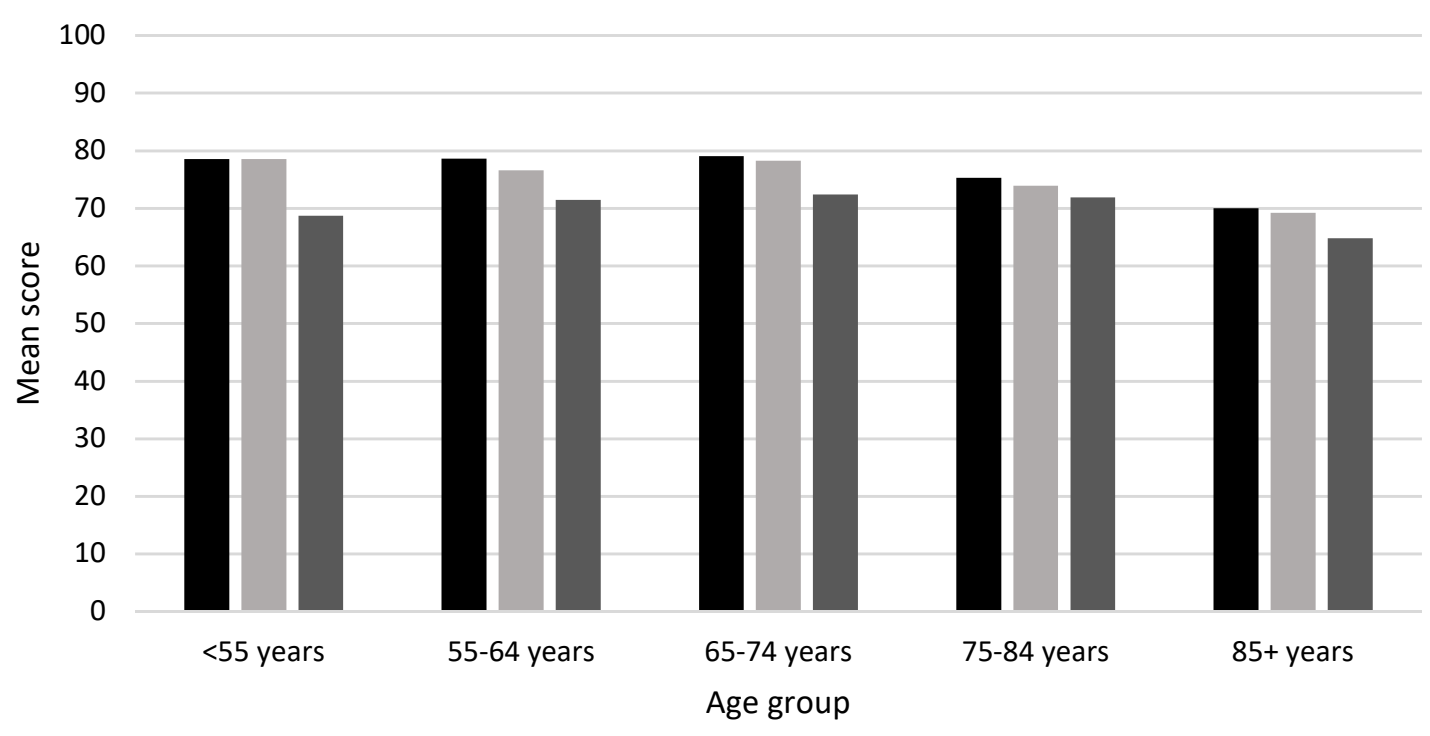

- Stage I/II $\quad$ Stage III $\quad$ Stage IV

b) Mean self-assesed health rating by ADT use and age group

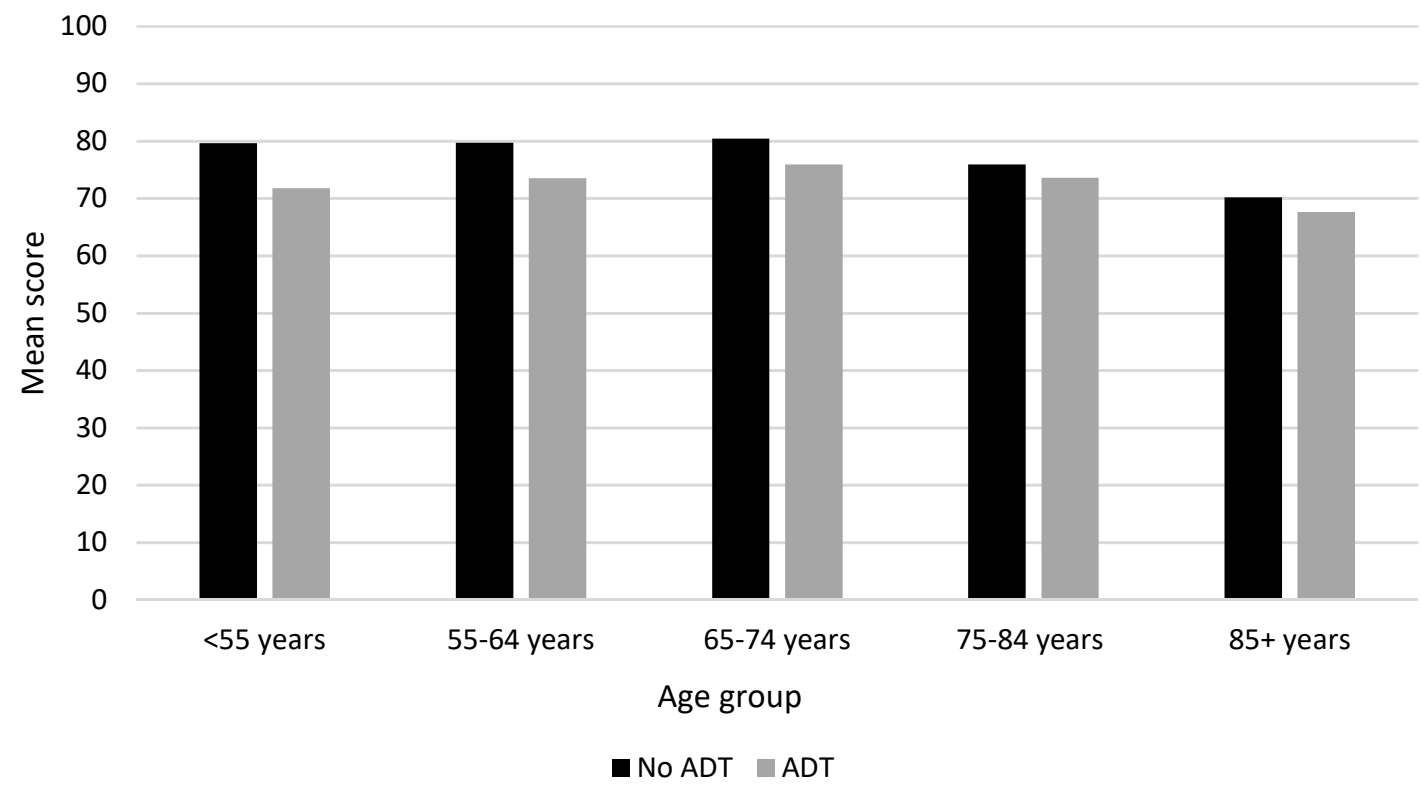

Figures represent predicted adjusted mean scores (adjusted for socio-economic deprivation and no. of other long-term conditions)

ADT: Androgen deprivation therapy

Results should be considered alongside the previously estimated minimally important difference for EQ-5D Selfassessed health (7 points). 